\title{
ENTRE DISPOSITIVOS E AGENCIAMENTOS: O DUPLO DELEUZIANO DE FOUCAULT
}

\author{
Eduardo PELLEJERO \\ Universidade Nova de Lisboa \\ epellejero@sapo.pt
}

1975. Foucault publicava Surveiller et punir, dando corpo a uma investigação que denotava um deslocamento dos seus interesses da constituição do saber à genealogia do poder. Não mudava apenas o objecto, mudavam, correlativamente, os conceitos. Entre outros, e sobretudo, o conceito de episteme deixa o lugar central que tinha ocupado até então para que seja ocupado pelo conceito de dispositivo (nada menos que 39 ocorrências, quando nunca antes tinha sido utilizado, fora dos cursos do College de France desse mesmo ano Les anormaux e «Il faut défendre la société»).

E Foucault tem nisto, sobretudo, uma dívida com Deleuze, com quem na época colabora no Groupe d'information sur les prisons; neste sentido, escreve: "eu não saberia medir por referências ou citações o que este livro deve a Gilles Deleuze e ao trabalho que faz com Félix Guattari” (FouCAult, 1975, p. 29 ). Trata-se da mesma dívida que reconhece um ano mais tarde no College de France; então atribui a razão do seu novo trabalho às "ofensivas dispersas e descontínuas" como as da anti-psiquiatria, mas sobretudo "à eficácia de algo - eu não ouso dizer um livro - como L'Anti-Oedipe [...] livro, ou, antes, coisa, acontecimento" (FoUCAULT, 1997, p. 7).

Foucault fala grandiloquentemente, mas não entra em precisões. Diz-nos que tem uma dívida para com Deleuze, não o que lhe deve.

1977. Será necessário esperar um par de anos para desvendar o mistério. Assim, no prefácio à edição americana de L'Anti-Oedipe, Foucault oferece-nos uma lista das noções que lhe chamaram a atenção: «multiplicidades, fluxos, dispositivos, conexões».

O conceito de dispositivo, então, que Foucault assimila ao de agenciamento, é um conceito do qual reconheceria a paternidade deleuziana (FOUCAULT, 1994, p. 133 - 136).

1972. Mas voltemos um segundo atrás, porque em L'Anti-Oedipe falava-se certamente de complexos, formações, maquinações, regimes, mas as noções de dispositivo e de agenciamento não aparecem em primeiro plano. Os principais críticos de Deleuze, em todo o caso, não dão conta da sua existência (assim, por exemplo, Mengue faz da noção de 
agenciamento um sintoma da ruptura com L'Anti-Oedipe, e Zourabichvili, no Vocabulaire, afirma que o conceito de agenciamento substitui o de «máquinas desejantes» a partir do livro sobre Kafka ${ }^{1}$ ).

Confunde-se Foucault, que escreve o seu prólogo em 77, depois da publicação de Kafka? Ou é sensível a algo que passa despercebido ao grosso dos leitores de L'Anti-Oedipe?

Bom, tudo é possível, digo, não podemos saber realmente o que passava pela cabeça de Foucault, mas a verdade é que, ainda que escassas, já encontramos ocorrências de ambos os términos em L'Anti-Oedipe. Pelo menos duas:

1) Primeiro, falando das regras de parentesco, Deleuze e Guattari referem-se a um «dispositivo matrimonial»:

Os etnólogos não deixam de dizer que as regras de parentesco não são aplicadas nem aplicáveis aos matrimónios reais: não porque estas regras sejam ideais, senão, pelo contrário, porque determinam pontos críticos nos quais o dispositivo se volta a por em marcha com a condição de estar bloqueado, e se situa necessariamente numa relação negativa com o grupo. É aí que aparece a identidade da máquina social com a máquina desejante (DELEUZE; GUATTARI, 1973, p. 178).

2) E, em seguida, no final do capítulo três, aparece pela primeira vez explicitamente a ideia de «agenciamento maquínico»: "Substituir o sujeito privado da castração [...] por agentes colectivos, que remetem a agenciamentos maquínicos. Reverter o teatro da representação na ordem da produção desejante: a tarefa por excelência da esquizoanálise" (DELEUZE; GUATTARI, 1973, p. 324).

São apenas duas ocorrências, mas dão conta do surgimento de uma noção que estava a cobrar vida. Numa entrevista do mesmo ano, ainda, Deleuze assinalava a possibilidade de pensar a linguagem, para além do sujeito e da estrutura, como um "sistema de fluxos contínuos de conteúdo e expressão, recortado pelos agenciamentos maquínicos de figuras discretas e descontínuas" (DELEUZE, 2002, p. 35), como uma hipótese que ainda não tinham desenvolvido suficientemente.

E a verdade é que nas aulas de Deleuze, às que vamos tendo acesso mais ou menos asistematicamente, começa a falar-se a partir de 73, e cada vez com maior insistência, de

\footnotetext{
${ }^{1}$ Cf. Mengue, G. Delenze on le système du multiple, 1997, p. 61 y Zourabichvili, Le vocabulaire de Delenze, 2003, pp. 8-9.
} 
dispositivos e de agenciamentos, preparando o caminho que levará à instauração do conceito de agenciamento em $K a f k a^{2}$.

1975-1977. O conceito, enquanto tal, continua a ganhar importância. Foucault fala de dispositivo disciplinário, dispositivo carcerário, dispositivos de poder, dispositivos de saber, dispositivo de sexualidade, dispositivo de aliança, dispositivo de subjectividade, dispositivo de verdade, dispositivos de segurança, dispositivo estratégico de relações de poder, etc., etc. Só em La volonté de savoir, encontramos 70 ocorrências do conceito (mesmo se desaparecerá por completo nos seguintes volumes da Histoire de la sexualité).

Ou então Foucault fala de agenciamentos: «agenciamento panóptico» (FOUCAULT, 1975, p. 210), «agenciamento político da vida» (FouCAULT, 1976, p. 163), etc. Porque Foucault fala indistintamente de agenciamento e dispositivo, ainda que certamente faça do agenciamento um uso muito restrito (1 ocorrência em Surveiller et punir, 4 em La volonté de savoir).

Em todo o caso, o conceito ganha em precisão. Entre outros, Edgardo Castro propõe considerar para a definição foucaultiana de dispositivo três elementos essenciais:

1) O dispositivo é a rede de relações que se podem estabelecer entre elementos heterogéneos: discursos, instituições, arquitecturas, regulamentos, leis, medidas administrativas, enunciados científicos, proposições filosóficas, morais, filantrópicas, o dito e o não-dito. 2) $O$ dispositivo estabelece a natureza do nexo que pode existir entre estes elementos heterogéneos. Por exemplo, o discurso pode aparecer como programa de uma instituição, como um elemento que pode justificar ou ocultar uma prática, ou funcionar como uma interpretação a posteriori desta prática, oferecer-lhe um campo novo de racionalidade. 3) $O$ dispositivo é uma formação que num momento dado teve como função responder a uma urgência [...] tem assim uma função estratégica, como, por exemplo, a reabsorção de uma massa de população flutuante que era excessiva para uma economia mercantilista [assim, o hospital geral, pode funcionar como dispositivo de controlosujeição da loucura] (CASTRO, 2004, p.102).

1975. Entretanto, claro, aparece o livro sobre Kafka. E então encontramos que o conceito de agenciamento, contemporaneamente ao que se passava com Foucault e à noção de dispositivo - ganhou a maior importância para Deleuze. Com efeito, para além do uso que vinham a fazer desde 72, no último capítulo, Deleuze e Guattari abordam frontalmente a definição do conceito. Temos, portanto, «Qu'est-ce qu'un agencement?», texto que certamente não terá passado despercebido a Foucault.

\footnotetext{
2 Por exemplo, na aula de 15 de Fevereiro de 1973, dá-se uma discussão entre Richard Pinhas e Lyotard em torno do «dispositivo analítico», e pelo menos desde a aula de 12 de Fevereiro de 1973 é frequente que Deleuze fale de «agenciamentos» e de «agenciamentos maquínicos», assim como que comece a introduzir exemplos que se tornariam canónicos a partir de Mille Plateaux.
} 
O que é um agenciamento? Em princípio, é uma alternativa conceptual ao sujeito e à estrutura, que permite a Deleuze - as palavras são de Philippe Mengue - "refundar uma teoria da expressão, eliminando qualquer traça «representativa» na função de expressão, e contornando toda a teoria da linguagem e dos signos (do significante) de Saussure" (MENGUE, 1997, p. $61-62)$.

Como funciona? Basicamente, relacionando os fluxos semióticos com os fluxos extrasemióticos e as práticas extra-discursivas, para além das relações de significante a significado, de representante a representado: trata-se de uma relação de implicação recíproca entre a forma do conteúdo (regime de corpos ou maquínico) e a forma da expressão (regime de signos ou de enunciação). Neste sentido, qualquer agenciamento tem duas caras:

Não há agenciamento maquínico que não seja agenciamento social de desejo, não há agenciamento social de desejo que não seja agenciamento colectivo de enunciação [...] E não basta dizer que o agenciamento produz o enunciado como o faria um sujeito; ele é em si mesmo agenciamento de enunciação num processo que não permite que nenhum sujeito seja assignado, mas que permite por isto mesmo marcar com maior ênfase a natureza e a função dos enunciados, uma vez que estes não existem senão como engrenagens de um agenciamento semelhante (não como efeitos, nem como produtos). [...] A enunciação precede o enunciado, não em função de um sujeito que o produziria, senão em função de um agenciamento que converte a enunciação na sua primeira engrenagem, junto com as outras engrenagens que vão tomando o seu lugar paralelamente (DELEUZE; GUATTARI, 1975, p. 147 - 152 ).

Há outra característica fundamental dos agenciamentos: qualquer agenciamento apresenta, por um lado, uma estratificação mais ou menos dura (digamos, os dispositivos de poder; Deleuze diz: "uma concreção de poder, de desejo e de territorialidade ou de reterritorialização, regida pela abstracção de uma lei transcendente" (Ibid, p. 153)), mas por outro compreende pontas de desterritorialização, linhas de fuga por onde se desarticula e se metamorfoseia (“onde se liberta o desejo de todas as suas concreções e abstracções”, diz Deleuze ( Ibid, p. 154)).

Adivinhamos aqui o problema que projectará Deleuze sobre o uso que faz Foucault da noção. Porque o problema de Deleuze não se esgota na determinação dos dispositivos nos quais nos encontramos comprometidos, senão que a partir dessa determinação lança a questão que atribui a Kafka: "Quando é que se pode dizer que um enunciado é novo?, para bem ou para mal; quando é que se pode dizer que um novo agenciamento se está a esboçar?, diabólico ou inocente, ou mesmo ambas as coisas ao mesmo tempo" (DELEUZE; GUATTARI, 1975, p. 148). 
1977. Chegamos então ao momento da inevitável confrontação. Este texto que Deleuze escreve depois da publicação de La volonté de savoir (1976), e que alegadamente é remetido, através de François Ewald, de acordo com o testemunho deste último, para transmitir o seu apoio a Foucault, que atravessava uma crise (e já voltaremos a esta crise). Este texto, que iria ser publicado quase vinte anos mais tarde em Le magazine littéraire (n³25, Outubro 1994) sob o título «Désir et plaisir» ${ }^{3}$, no qual Deleuze se entrega a uma análise crítica dos últimos trabalhos de Foucault.

O que é que diz Deleuze de Surveiller et punir? Em princípio, e de um modo geral, que representa uma «profunda novidade política» com relação ao modo em que concebe o poder. Em seguida, que a respeito do trabalho do próprio Foucault, implica uma superação da dualidade que existia entre formações discursivas e não-discursivas, ou, melhor, «uma razão das suas relações» (mas isto, como víamos, é o que definia o seu próprio conceito de agenciamento).

Deleuze considera, por outra parte, que La volonté de savoir significa «um passo adiante» a respeito de Surveiller et punir. Primeiro, porque os dispositivos de poder passam a ser «constituintes» (da sexualidade) e não apenas normalizantes. Segundo, porque não se limitam a formar saberes, senão que são constitutivos de verdade (da verdade do poder). Por fim, porque já não se referem a «categorias» negativas - a loucura ou a delinquência como objectos de encerramento -, senão a uma categoria positiva: a sexualidade.

Isto no que diz respeito à avaliação positiva do trabalho de Foucault, porque, pelo que resta, a verdade é que tudo são críticas. Vou limitar-me às mais pertinentes para a questão dos dispositivos. E assim seriam duas:

1) Em primeiro lugar, Deleuze não consegue reduzir os agenciamentos do desejo aos dispositivos do poder. Para Deleuze um agenciamento de desejo comporta dispositivos de poder, mas sempre entre outros componentes do agenciamento. Os dispositivos de poder surgem onde se operam re-territorializações, é tudo. Deleuze escreve:

Os dispositivos de poder seriam então uma componente dos agenciamentos. Mas os agenciamentos comportariam também pontas de desterritorialização. Brevemente, não seriam os dispositivos de poder que agenciariam, nem seriam constituintes, senão os agenciamentos de desejo que propagariam formações de poder seguindo uma das suas dimensões. O que me permitiria responder à questão, necessária para mim, desnecessária para Michel:

\footnotetext{
${ }^{3}$ Deleuze, «Désir et plaisin», Magazine littéraire, n 325, octobre 1994, p. 59-65; reeditado em Deleuze, Deux régimes de fous: Textes et entretiens 1975-1995, Edición de David Lapoujade, Paris, Minuit, 2003 (citamos sempre esta edição).
} 
como é que o poder pode ser desejado? A primeira diferença seria então que, para mim, o poder é uma afecção do desejo (DELEUZE, 2003, p. 115).

2) Em segundo lugar, Deleuze vê no deslocamento do princípio que define um campo social dado, das contradições às estratégias, um passo em frente; mas é uma ideia que não acaba por convencê-lo. Uma sociedade não se contradiz, mas também não se estrategiza: o primeiro é que foge, o social foge por todas as partes. Cito novamente Deleuze:

Ainda aí, eu reencontro o primado do desejo, uma vez que o desejo está precisamente nas linhas de fuga [...] Confunde-se com elas [...] As linhas de fuga, os movimentos de desterritorialização não me parecem ter equivalente em Michel, como determinações colectivas históricas. Para mim não há o problema de um estatuto dos fenómenos de resistência: uma vez que as linhas de fuga são as determinações primeiras [...] são linhas objectivas que atravessam uma sociedade [...] De onde o estatuto do intelectual $e$ o problema político não serão teoricamente os mesmos para Michel e para mim (DELEUZE, 2003, pp. 117 - 118).

1977. O tom das notas de Deleuze sempre me pareceu muito agressivo, territorial, no sentido clássico (não deleuziano) da palavra. Digo: não parece que Deleuze pretenda animar Foucault, parece que quisera liquida-lo de vez. Esta é uma história muito mal contada.

Exemplo. Deleuze diz que Foucault the teria comentado que não suportava a palavra desejo, mesmo se era empregue de maneira inovadora, porque sempre que ouvia desejo pensava em carência, em repressão. A isto, Deleuze responde que, pela sua parte, não suporta a palavra prazer e que o desejo, para ele, não comporta nenhuma carência, que não é outra coisa que um agenciamento de heterogéneos (e a isto atribui, entre outras coisas, o modo inverso no qual se servem de Lawrence, ou o facto de que ele se interesse por Masoch enquanto que Foucault se interessa por Sade (ainda que mais tarde Foucault venha a renegar este «sargento do sexo»)).

Agora, a mim, isto faz-me imensa confusão, porque Foucault, que se diz profundamente influenciado por L'Anti-Oedipe, não pode ignorar que o que Deleuze entende por desejo não tem nada que a com a carência. E, de facto, sempre em 77, no prólogo que escrevia na edição americana, Foucault encarregava-se de desfazer qualquer mal entendido possível, opondo as teses deleuzianas sobre o desejo, que considera «de uma força revolucionária», aos "penosos técnicos do desejo - os psicanalistas e os semiólogos que registam cada signo e cada sintoma, e que quiseram reduzir a organização múltipla do desejo à lei binária da estrutura e da carência” (FOUCAULT, 1994, p. 135).

1986. Este episódio perde relevância, de qualquer modo, dez anos depois, quando Deleuze publica o livro especialmente dedicado a Foucault, onde pratica uma reavaliação 
sistemática da sua obra. Quero dizer que temos então uma leitura incomensurável dos conceitos foucaultianos (incomensurável com a leitura de 77), que se estenderá através de entrevistas e referências circunstanciais até à década de 90.

De 77 ficará apenas uma história: a história de uma crise. De uma crise de todas as ordens: política, vital, filosófica. É assim que Deleuze interpreta o longo silêncio que segue à La volonté de savoir: Foucault teria tido a sensação de que se teria fechado nas relações de poder. Deleuze comenta:

O fracasso final do movimento das prisões, depois de 1970, já entristecera Foucault; outros acontecimentos posteriores, à escala mundial, aumentaram essa tristeza. Se o poder é constitutivo de verdade, como conceber um «poder da verdade» que já não seja verdade do poder, uma verdade que derive das linhas transversais de resistência e já não das linhas integrais de poder? Como «franquear a linha»? (DELEUZE, 1986, p. 101).

Deleuze repete sistematicamente esta versão em todas as entrevistas que dá por ocasião da saída do seu livro. Sistematicamente, também, apela a este preciso fragmento de «La vie des hommes infâmes ${ }^{4}$ : “Aqui estamos, sempre com a mesma incapacidade para franquear a linha, para passar para o outro lado [...] Sempre a mesma eleição, do lado do poder, do que diz ou faz dizer [...]" (FouCAUlT, 1994, p. 241).

A teoria de que o pensamento procede por crises é cara a Deleuze, que a utiliza mesmo para dar conta do seu próprio percurso (entre o livro sobre Hume e Nietzsche et la philosophie contavam-se oito anos de silêncio), mas no caso específico de Foucault serve-lhe para orientar toda a sua leitura em torno da questão da resistência ao poder, que era princípio de desacordo nos setenta e resulta princípio de explicação nos oitenta.

Nos setenta, com efeito, havia problemas que se colocavam para Deleuze e não se colocavam para Foucault, e vice-versa. Nos oitenta, crise mediante, Foucault toma consciência de que os problemas não podem ser mais que os mesmos para ambos e que é no mesmo sentido que devem procurar uma solução: para além dos dispositivos de poder tem que haver uma dimensão para a luta, para a criação, para a resistência. Em uma entrevista de 1986 Deleuze preenche essa distância: "Por muito que invoque os focos de resistência, de onde vêm tais focos? Necessitará muito tempo para encontrar uma solução, uma vez que, de facto, se trata de cria-la" (DELEuZE, 1990, p. 126).

\footnotetext{
${ }^{4}$ Foucault, «La vie des hommes infâmes», Les Cabiers du chemin, no 29, 15 janvier 1977, pp. 12-29; reeditado em Foucault, Dits et écrits, op. cit., vol. III, pp. 237-253 (citamos sempre esta edição).
} 
Qual é esta solução? São, diz Deleuze, os processos de subjectivação como dobra das relações de força dos dispositivos de poder. Trata-se da constituição de modos de existência, da invenção de possibilidades de vida, da criação de territórios existenciais, seguindo regras facultativas, capazes de resistir ao poder como de furtar-se ao saber, mesmo se o saber intenta penetrá-las e o poder de reapropriar-se delas. A luta por uma subjectividade moderna passaria para Foucault por uma resistência às formas actuais de sujeição, passaria por individuar-nos para além das exigências do poder, aquém também, da nossa determinação como indivíduos com uma identidade constituída e conhecida, decidida de uma vez por todas.

Reconhecemos o tema do cuidado de si, o tema de uma estética da existência, que Foucault desenvolve a partir de L'usage des plaisirs. Não reconhecemos tão facilmente a que dimensão possam corresponder estes processos de subjectivação dentro do quadro da ontologia deleuziana. Como chamar a esta nova dimensão - pergunta-se Deleuze -, a esta relação consigo mesmo que já não é saber nem poder, e sem a qual não se poderia superar o saber nem resistir ao poder? (Idem, p. 135) Trata-se do prazer ou do desejo? (DELEUZE, 1986, p. 113).

1989. Uma vez afastado que Deleuze possa falar positivamente do prazer ${ }^{5}$, não ficaria mais que o desejo. Agora, podemos aceitar, como dizíamos, que Foucault visse um conceito revolucionário no desejo deleuziano, mas está fora de questão utilizar um qualquer conceito de desejo para ler a Histoire de la sexualité ${ }^{6}$.

Deleuze, que em «Désir et plaisir» opunha os dispositivos de poder aos agenciamentos de desejo, também o entenderá assim. Mas, de facto, o que encontramos como resposta é bastante confuso. Ora Deleuze fala indiferentemente de dispositivos e agenciamentos, trata-os como sinónimos (2003, p. 119), ora introduz um terceiro termo - o diagrama, espécie de esquema kantiano que estrutura puras relações de forças, e do qual derivam os dispositivos do poder e do saber, agenciando as formas irredutíveis da receptividade (o enunciável) e da espontaneidade (o dizível).

Prova disto é que no livro de 86, Deleuze põe no centro a noção de diagrama, que Foucault utiliza apenas em duas oportunidades em Surveiller et punir (e de resto não emprega

\footnotetext{
${ }^{5}$ Cf. Deleuze (2003, pp. 119-120): "Eu não posso dar ao prazer nenhum valor positivo, porque o prazer parece-me interromper o processo imanente do desejo, o prazer parece-me do lado dos estratos e da organização [...] É uma re-territorialização".

${ }^{6}$ Cf. Foucault, Dits et écrits, Paris, Gallimard, 1994a, vol. IV, p. 445: “-Você admite certo parentesco com Deleuze até certo ponto. Iria este parentesco até à concepção deleuziana do desejo? - Não, certamente não".
} 
o termo em nenhum outro texto), enquanto que no último artigo que publica a respeito «Qu'est-ce qu'un dispositif?», em 89, o conceito de diagrama desaparece por completo, sobrevivendo todas as suas propriedades na nova e definitiva definição de dispositivo.

De qualquer modo, o certo é que o campo social deixou de estar composto apenas por formações isoladas e imutáveis: só as estratificações do saber e do poder lhe proporcionam alguma estabilidade, mas em si mesmo é instável, agitado, cambiante, como se dependesse de um «apriori paradoxal», de uma «microagitação» (1986, p. 91). Não há dispositivo ou agenciamento que não implique, ao lado dos pontos que conecta, no seu diagrama, digamos, pontos relativamente livres ou libertados, pontos de criatividade, de mutação, de resistência (Idem, p. 51).

A resistência é primeira. É-o para Deleuze, e pode chegar a sê-lo para Foucault na medida em que a produção de subjectividade escapa aos poderes e aos saberes de um dispositivo para reinvestir-se nos de outro: a relação consigo mesmo - então - é uma das fontes de esses focos de resistência (Ibid, p. 111).

A tarefa é, então, alcançar as linhas de subjectivação que determinam a margem extrema de um dispositivo e esboçam a passagem de um dispositivo a outro: "faz falta chegar a dobrar a linha, para constituir uma zona vivível, onde poder alojar-se, tomar apoio, respirar - brevemente, pensar" (DELEUZE, 1990, p. 151).

1995. É neste sentido que Deleuze vai recusar violentamente as interpretações que vêem em Foucault um historiador. Para Deleuze, o que conta é a preocupação foucaultiana pela actualidade. Uma preocupação que nada tem a ver com um eventual retorno aos gregos, senão com as possibilidades que temos de constituir-nos como «si», para além do saber e do poder, com os processos de subjectivação irredutíveis aos códigos morais dos que dispomos.

Escreve Deleuze:

As formações históricas não lhe interessam [a Foucault] senão porque marcam aquilo do que saímos, o que nos envolve, aquilo com o que estamos em vias de romper para encontrar novas relações que nos expressem. A história não diz o que somos, senão aquilo do que estamos em vias de diferir, não estabelece a nossa identidade, senão que a dissipa em proveito do outro que somos. [...] Brevemente, a história é o que nos separa de nós mesmos, e o que devemos franquear e atravessar para pensar em nós mesmos (1990, p. 130).

E esta é a principal consequência de uma filosofia dos dispositivos: uma mudança de orientação, que se desvia da filosofia do Eterno para aprender o novo. Não predizer, diz Deleuze, senão estar atento ao desconhecido que toca à porta (2003, p. 323). 
2005. Para além de todas as alternativas de uma relação difícil, na qual «atirar rosas» não foi dos gestos mais frequentes, Deleuze encontra em Foucault um interlocutor privilegiado, um intercessor, como dizia ele.

Nesse sentido, o trabalho sobre a sua obra não se inscreve facilmente na história da filosofia. Por todas as partes vemos que a relação hermenêutica resulta desdobrada num agenciamento no qual deixam de ser relevantes a precedência e a autoridade, e onde a identidade do sujeito que conduz a crítica e a do sujeito da mesma se desdobram e confundem permanentemente.

A pergunta pela pertinência ou pela adequação da leitura não perde todo o seu sentido, mas é deslocada por outras questões que dizem respeito à possibilidade de relançar as filosofias de Foucault e de Deleuze num só movimento, e "para que pensar, sempre, se produza no pensamento" (DELEUZE, 1986, p. 127).

Deleuze não pretendia dizer o que teria querido dizer Foucault. Quis apenas extrair um duplo (DeleuZE, 1990, p. 117). E com os duplos, já se sabe o que passa. Nunca se acaba por saber qual é qual.

Fica para nós decidir se vamos trabalhar para descobrir o impostor, ou para multiplicar os espelhos.

Traduzido do castelhano por Susana Guerra

\section{Referências}

CASTRO,

El vocabulario de Michel Foucault: Un recorrido alfabético por sus temas, conceptos y autores. Buenos Aires: Prometeo, 2004.

DELEUZE, Gillis. Foucault. Paris: Éditions de Minuit, 1986.

Pourparlers 1972-1990. Paris: Éditions de Minuit, 1990.

Minuit, 2002.

L'île déserte et autres textes: Textes et entretiens 1953-1974. Paris: Éditions de

Deux régimes de fous: Textes et entretiens 1975-1995. Edición de David Lapoujade. Paris: Éditions de Minuit, 2003.

DELEUZE, Gillis; GUATTARI, Felix. Capitalisme et schizophrénie: L'Anti-Oedipe. 2a edição. Paris: Éditions de Minuit, 1973.

Kafka: Pour une litterature mineure. Paris: Éditions de Minuit, 1975.

FOUCAULT, Michel. Surveiller et punir: naissance de la prison. Paris: Gallimard, 1975.

Histoire de la sexualité 1: La volonté de savoir. Paris: Gallimard, 1976. 
Dits et écrits. Paris: Gallimard, 1994. vol. III.

Dits et écrits, Paris: Gallimard, 1994a. vol. IV.

«Il faut défendre la société». Cours au Collège de France (1975-1976). Paris:

Gallimard, 1997.

MENGUE, Gilles Deleuze ou le système du multiple. Paris: Kimé, 1997.

ZOURABICHVILI,

..Le vocabulaire de Deleuze. Paris: Ellipses, 2003. 